\title{
O alto, o baixo e o médio ${ }^{1}$
}

\section{The high, the middle, and the low}

Laura Vazquez

Universidade de Buenos Aires/CONICET

DOI: 10.28998/2317-9945.2019n63p319-321

O que está em crise são as "bierarquias" da arte.

(Carlos Nine)

Continuar falando em termos de "alto" e "baixo" na arte pode ser inútil, se é que alguma vez teve sentido e se é que ainda é conveniente falar de arte. No entanto, no quadrinho, a questão parece ser mais complexa. O fato de que este meio se constitui em uma "zona fronteiriça" fez com que, a partir da década de 60, artistas, cineastas e críticos - como Umberto Eco, Claude Moliterni, Alain Resnais, Pier Paolo Pasolini e Federico Fellini - se sentissem atraídos pelo seu cruzamento de gêneros e linguagens.

Na Argentina, Oscar Masotta, Pablo de Santis, Guillermo Saccomanno, Juan Sasturain, Oscar Steimberg, Jorge Rivera, Eduardo Romano e Carlos Trillo não se abstiveram dessa agenda de interesses na qual os conflitos entre o mercado, a arte, a cultura popular e a política encontravam na sua linguagem uma textualidade "ideal" para ler tensões e problemas. Daí se começou a discutir a "verdadeira natureza" dos quadrinhos produzidos industrialmente e a buscar uma definição que evocasse seu "valor" e "função", algum componente irredutível de sua prática específica.

De acordo com Rivera (1992), os argumentos favoráveis eram vários: alguns citavam a origem milenar da linguagem desenhada e começavam seus livros falando das Cavernas de Altamira, enquanto outros dissertavam sobre os originais de Alberto Breccia ou Harold Foster como prova contundente da existência da Nona Arte. Dissecar de maneira reflexiva os materiais originais sempre resultava num saldo favorável: "os quadrinhos são Arte". Já a expressão utilizada por Oscar Masotta para definir uma linguagem híbrida ("literatura desenhada") resolve um problema referente à integração ao cânone das artes consagradas por instituições e campos de reconhecimento intelectual.

O roteirista Héctor Oesterheld assegurava que, assim como o cinema tinha atingido sua maturidade como linguagem, "não há razão para que o mesmo não ocorra com os quadrinhos" (revista Dibujantes, novembro de 1965). E, quando não se buscava a tutela da arte ou o caminho da consagração estética, a fórmula da margem estava sempre ali para produzir táticas intersticiais e de subversão ao interior do cânone cultural. Desta forma, os quadrinhos foram agrupados com os gêneros marginais que incluíam desde as formas orais

\footnotetext{
${ }^{1}$ Texto publicado originalmente em VAZQUEZ, Laura. Lo alto, lo bajo y lo del medio. In: VAZQUEZ, Laura. Fuera de cuadro: ideas sobre historieta. Buenos Aires: Agua Negra, 2012. Tradução de Jozefh Fernando Soares Queiroz (Universidade Federal de Alagoas).
} 
do folclore ao roteiro teatral, o gênero criolo, o policial, a canção popular, a ficção científica, a literatura infantil, a crônica jornalística, a literatura "rosa" ou o folhetim.

Essa posição representativa dos autores anteriormente destacados assume a margem como traço de uma criação original, autêntica, representativa e da "identidade dos argentinos". Se a cultura oficial participa da concepção eurocêntrica de arte e cultura, a produção construída a partir da periferia deriva do refúgio para construir estratégias de reconhecimento. Esta tensão entre o nacional e o internacional e a referência a "um tempo dourado e melhor" (décadas de 40 e 50, auge da indústria dos quadrinhos na Argentina) são indicadores de um discurso no qual a eficácia e os limites da cultura "à (na) margem" do sistema internacional globalizado têm como revés a busca pela legitimação.

Concordando com Andreas Huyssen, a distinção entre alta arte e cultura de massas (oposição que acompanhou a trajetória da modernidade ocidental desde o romantismo ao pós-modernismo) continua existindo porque sempre haverá diferenças de qualidade e ambição entre os diferentes produtos culturais, diferentes demandas e níveis de complexidade. Mas essa divisão (entre literatura séria e arte midiática) já não é vertical nem opera de um lado ou de outro do binômio. Sua proposta é substituir a relação de valor hierárquico por uma configuração lateral ou horizontal, levando em conta que já

não nos enfrentamos, por um lado, com uma indústria cultural hegemônica e, por outro, com seu contrário alto e autônomo (como sugeriam os escritos de Adorno ou Clement Greenberg), mas sim com um mercado massivo de nichos quantitativamente e qualitativamente diferenciados para todo tipo de consumo cultural (HUYSSEN, 2003).

Para Huyssen, ao invés de celebrar o novo (seguindo o sinal trágico do vanguardismo), podemos enfocar nas complexidades da repetição, da montagem, da reescrita e das sobreimpressões e destacar a "intertextualidade sugestiva, a cópia criadora, o poder de um texto para questionar os hábitos enraizados através de estratégias visuais ou narrativas, a habilidade de transformar o uso dos meios, etc.” (HUYSSEN, 2003, p. 71). Sua sugestão é explícita e reveladora: posicionar-se em defesa de um modernismo brechtiano ${ }^{2}$ e encontrar um lugar para a crítica política eficaz.

Quando os pioneiros do campo escreveram seus textos, a distinção alto/baixo estava em plena vigência. Reler esses textos fundadores é recolocar em questão elementos de um projeto que hoje parece "distante demais", mas que, no entanto, perdura. No "meio", em uma zona fronteiriça, contraditória e híbrida, a crítica dos quadrinhos não conseguiu sair da encruzilhada. Já sabemos que o olho por si só e o gosto treinado não podem dar conta da diferença. Então, como superar a inquietação? Porque, às vezes, simplesmente, não se pode recomeçar. Ou se pode? Creio que somente a partir do reconhecimento dessa diferença é que podemos reabilitar o campo, reformular as perguntas e fazer o que melhor sabemos fazer.

\footnotetext{
${ }^{2}$ Relativo à ou próprio da técnica dramática que faz uso de exposição dialética e clara, linguagem inteligível e concentração de todos os meios teatrais, visando transmitir uma visão cívica, anárquica, proletária ou revolucionária, ou obrigar a uma reflexão, lançando mão, ademais, de projeções, de canções cujas letras acompanham as ações, de narração lenta dos episódios e de iluminação intensa.
} 
Referências:

HUYSSEN, Andreas. Alto/bajo en un campo expandido. Revista Zigurat n. 4.

Departamento de Ciências da Comunicação, Faculdade de Ciências Sociais, Universidade de Buenos Aires, 2003.

MASOTTA, O. La historieta en el mundo moderno. Buenos Aires: Paidós, 1980.

RIVERA, J. B. Panorama de la historieta en la Argentina. Buenos Aires: Coquena Grupo Editor, 1992.

ROMANO, E. Breve examen de la historieta. In: FORD, A.; RIVERA, J. B.; ROMANO, E. Medios de comunicación y cultura popular. Buenos Aires: Legasa, 1985.

SACCOMANNO, G.; TRILLO, C. Historia de la historieta argentina. Buenos Aires: Record, 1980.

SASTURAIN, J. El domicilio de la aventura. Buenos Aires: Colihue, 1995.

STEIMBERG, O. Leyendo historietas. Estilos y sentidos de un "arte menor". Buenos Aires: Nueva Visión, 1997.

Olhares imprescindíveis.

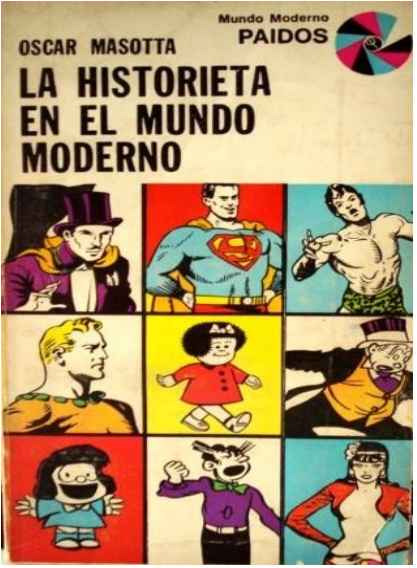

paraleer
alpato domald

comunicación

de masa

y colonialismo

ariel dorfman

armand mattelart

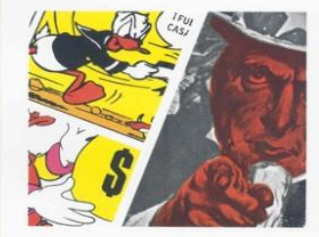

Xe

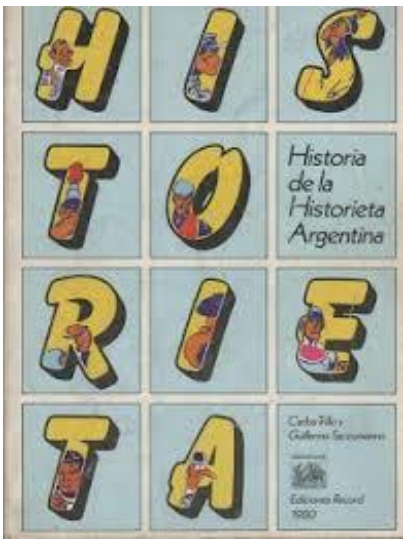

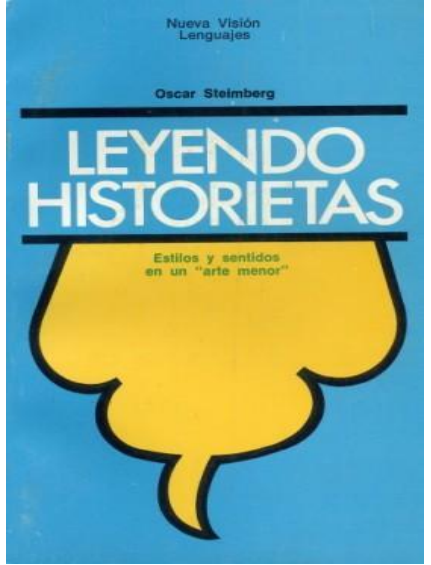

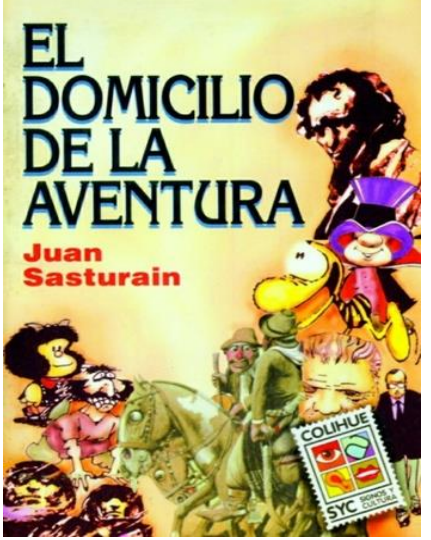

